\title{
Article
}

\section{Turbine Blade Temperature Field Prediction Using the Numerical Methods}

\author{
Miroslav Spodniak (D), Karol Semrád *(D) and Katarína Draganová (D) \\ Faculty of Aeronautics, Technical University of Košice, Rampová 7, 04121 Košice, Slovakia; \\ miroslav.spodniak@tuke.sk (M.S.); katarina.draganova@tuke.sk (K.D.) \\ * Correspondence: karol.semrad@tuke.sk; Tel.: +421-55-602-6158
}

Citation: Spodniak, M.; Semrád, K.; Draganová, K. Turbine Blade Temperature Field Prediction Using the Numerical Methods. Appl. Sci. 2021, 11, 2870. https://doi.org/ 10.3390/app11062870

Academic Editor: José A.F.O. Correia

Received: 1 March 2021

Accepted: 22 March 2021

Published: 23 March 2021

Publisher's Note: MDPI stays neutral with regard to jurisdictional claims in published maps and institutional affiliations.

Copyright: (c) 2021 by the authors. Licensee MDPI, Basel, Switzerland. This article is an open access article distributed under the terms and conditions of the Creative Commons Attribution (CC BY) license (https:// creativecommons.org/licenses/by/ $4.0 /)$.
Featured Application: The results of the research presented in the proposed article in terms of a novel quick and precise methodology for temperature prediction using numerical methods can be applied to research, development and monitoring engine parts. The methodology can be applied in aviation to increase the reliability and lifetime of turbines and hot parts of any jet engine and to reduce not only maintenance but also research and development costs due to the significantly lower computational time demands. The advantage of this methodology is also that it can be applied to any engine parts without the need for artificial neural network modification; the optimization process must only be performed on the CFD model.

Abstract: Nowadays, material science and stress characteristics are crucial in the field of jet engines. There are methods for fatigue life, stress, and temperature prediction; however, the conventional methods are ineffective and time-consuming. The article is devoted to the research in the field of application of the numerical methods in order to develop an innovative methodology for the temperature fields prediction based on the integration of the finite element methods and artificial neural networks, which leads to the creation of the novel methodology for the temperature field prediction. The proposed methodology was applied to the temperature field prediction on the surface blades of the experimental iSTC-21v jet engine turbine. The results confirmed the correctness of the new methodology, which is able to predict temperatures at the specific points on the surface of a turbine blade immediately. Moreover, the proposed methodology is able to predict temperatures at specific points on the turbine blade during the engine runs, even for the multiple operational regimes of the jet engine. Thanks to this new unique methodology, it is possible to increase the reliability and lifetime of turbines and hot parts of any jet engine and to reduce not only the maintenance but also the research and development costs due to the significantly lower time demands. The main advantage is to predict temperature fields much faster in comparison to the methods available today (computational fluid dynamics (CFD), etc.), and the major aim of the proposed article is to predict temperatures using a neural network. Apart from the above-mentioned advantages, the article's main purpose is devoted to the artificial neural networks, which have been until now used for many applications, but in our case, the neural network was for the first time applied for the temperature field prediction on the turbine blade.

Keywords: temperature field; turbine blade; jet engine; artificial neural network; numerical analysis; prediction model

\section{Introduction}

A pressure turbine of the jet engine is the part where the thermal energy is transformed into mechanical work [1]. The energy transformation is ensured by increasing the hot gas's speed between the turbine blades and by their impact on the airfoils of the turbine blades. Hot gases emit significantly high-temperature, which has an impact on the turbine blades. In order to predict this impact, a number of analyses for particular engine parts 
must be carried out [2]. Numerical simulations of the temperature fields of the turbine blades are required for every element of a gas turbine during the design process of the engine. However, as it is reviewed below, there are also many other cases that require the determination of the temperature fields of the turbine blades. Increasing the turbine inlet temperature leads to the improvement of the efficiency, but the temperature cannot exceed the melting point of the material. Therefore, blade metal temperature distribution and temperature gradients are the most important parameters when determining the blade life. The temperature of the blade has a significant impact on the jet engine lifetime. It also must be considered that during the jet engine operation, there are multiple phases, such, for example, nominal regime, idle run, maximal regime, etc. with are characterized by completely different temperatures. Therefore, it is essential to know the temperature fields on the surfaces of the turbine blade also for the specific regimes of the jet engine operation. Mentioned facts are clearly proving the importance of the turbine temperature field prediction.

There are multiple reasons why it is necessary to know the temperature fields of the turbine blades. For example, in [1], the study of the temperature of the cooling turbine blade is presented. In addition, for the Campbell diagram creation, the temperature fields of the turbine blade are needed because, with the increase of the temperature, natural frequencies are decreasing [3]. Another application area where the knowledge of temperatures of the turbine blade is necessary [4] is the fatigue life analysis, particularly considering the cyclic loading, as presented in [5-7]. The next example is the sensitivity study, where the knowledge of the temperature fields must be included when the simulations of the turbine blade application are performed [8]. For the sensitivity study presented in [4], the temperature fields of the turbine blade must be available for the multiple regimes [9]. When simulating the models of internally cooled gas turbine blades [10], the temperature characteristics also must be used. An example of the simulation of the cooled gas turbine blades is shown in [10], where the impact of the internal cooling system is studied [11,12]. Another example, where the temperature fields are needed, is presented in [13], where the effect of internal cracks on the surface profile change due to low loading of a turbine blade using the finite element method is studied.

From this brief overview, it is obvious that the need for the temperature field prediction of the turbine blade is indisputable because it serves as the input of many simulations and analyses and can help to significantly improve the results of many types of analyses. Nowadays the numerical methods based on the finite element method (FEM) or computational fluid dynamics (CFD) methods are used for this purpose [14-16]. The application of the CFD [17] and FEM [18] methods for the surface temperature field of the turbine blades is nowadays widespread; however, the calculation of the turbine blade surface temperature during the multiple regimes can be time-consuming. The use of the CFD and FEM methods for the temperature field prediction during the design phase can take significant time not only due to the model creation and boundary condition application but also due to the solution process itself, which can take for complex or detailed FEM models several hours and in general, these calculations must be performed many times, particularly during the optimization process. Therefore, the interesting solution how to eliminate the time demands seems to be the application of the novel method, based on the integration of the artificial neural networks (ANN), which would decrease the solution time significantly.

The ANNs are nowadays used mainly in electrical and electronic engineering; however, they can also be applied for the solution of mechanical engineering tasks. They can be used, for example, for the prediction of the various physical and mechanical parameters of the different technical systems or their elements in industrial applications. For example, in the study [19], research is focused on the investigation of the mas detection and its impact on the simple beam, which is possibly applicable on the turbine blade. In this case, the ANN is used to predict mechanical parameters. The ANN can also be used for the stress, fatigue lifetime, or creep prediction of the jet engine turbine parts $[20,21]$. There 
are some applications of the ANN for the temperature, fatigue life or other parameters determination [22-25].

As it was already mentioned, calculation of the temperature fields for the turbine blade using the CFD and FEM methods is not a trivial issue, mainly due to the jet engine operation in multiple types of regimes. For instance, in the case of the one regime calculation, the analysis would take, for example, an hour [26]. In the load case of 100 operations of the jet engine, the analysis would take $100 \mathrm{~h}$, and if there is a need to predict temperature fields of the turbine blade in real time, completely different and more complex methods must be selected $[27,28]$.

Our research is originally applied for the temperature prediction of the turbine blade using the integration of the ANN methodology and the data obtained from the CFD analyses, utilizing the advantages of both methods. The originality of the paper lies in the prediction of temperatures using ANN, which can, for some cases, replace the CFD method. The developed method was consequently applied and verified on the iSTC-21v small jet engine [29-31]. This jet engine with the designation iSTC-21v is the experimental single shaft jet engine, which has been a part of the continuous ongoing research performed in the Laboratory of Intelligent Control Systems of Aircraft Engines in Faculty of Aeronautics of the Technical University of Kosice [32-34]. Thanks to the long-term research performed in our laboratory on the iSTC-21v jet engine dealing mainly with its control systems, for optimization, of which many additional characteristics such, for example, magnetic, temperature, pressure, etc. had to be measured and studied, the engine and its characteristics were analyzed in details. The article deals with the following research based on the numerical approach followed by the whole series of simulations. One part of this research presented in the article is focused on the integration of the existing measured characteristics, which served as a basis for the numerical simulations. Moreover, thanks to the knowledge and experience obtained during the design of control algorithms, the cybernetic approach was implemented. In this way, it is possible to improve the efficiency of the design or necessary modification of the component without the need for time-consuming calculations because the methodology presented in the article based on the artificial neural networks can be used almost in real time.

\section{Materials and Methods}

Research in the area of jet engines is extensive, especially in the field of the stress and life prediction of the particular parts of the jet engines. The current trends involve the extension of the lifetime and durability of the components and also the increasing the performance of the jet engine by the increasing of the temperatures in the pressure turbines. Considering the research of the aviation materials and their applications in the turbine parts, it is essential not only to choose but also to monitor and predict the mechanical parameters of the particular parts of the jet engine. The temperature prediction is essential for the monitoring systems of the new jet engines. As it was overviewed, conventional methods are time-consuming for the prediction of the temperature fields of the turbine blades, especially if multiple operation regimes of the jet engine are considered. However, the ANN seems to have a promising future in this area because it offers a convenient solution how to considerably eliminate the calculational time demands.

\subsection{Methodology}

To predict the thermal fields on the surface of the turbine blade, the new methodology involving the creation of the geometrical model of the engine part with the corresponding CFD analysis with the defined boundary conditions, followed by the utilization of the artificial neural network utilization for the prediction of the temperature fields was developed. In Figure 1, the proposed methodology applied to the iSTC-21v jet engine can be seen. However, the proposed methodology can be analogically applied to any jet engine or its parts. 


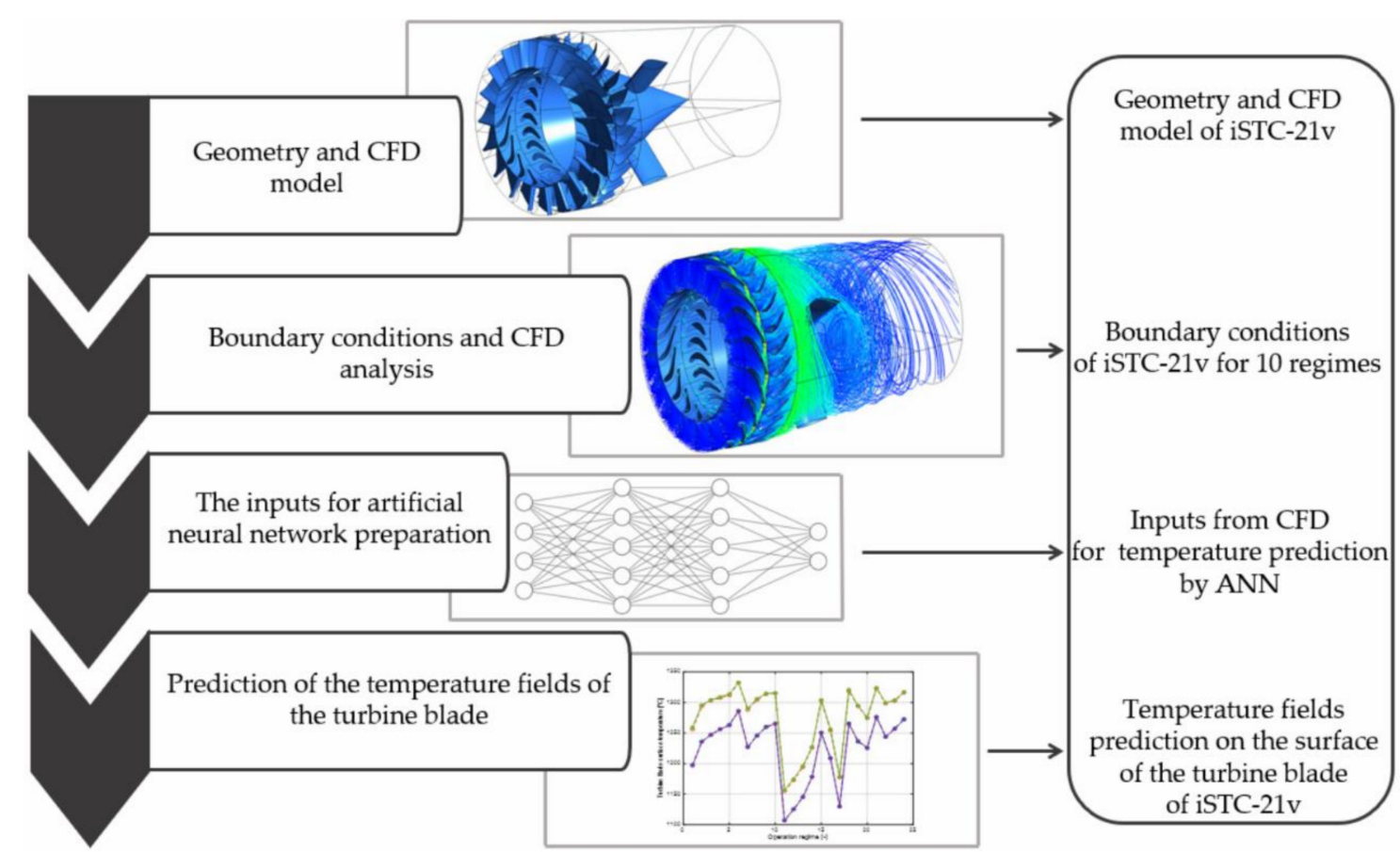

Figure 1. Methodology for the prediction of the turbine blade surface temperature fields.

According to the methodology presented in Figure 1, first, the 3D model of the investigated object must be created. The model must be prepared according to the geometry in accordance with the technical documentation of the product. In our case, the methodology was applied to the turbine parts of the iSTC-21v jet engine (Figure 2), which is described in the right part of Figure 1. The main goal of the methodology described in the previous figure is to create a method, which is able to predict temperature fields on the turbine blade surface much faster than the CFD method.

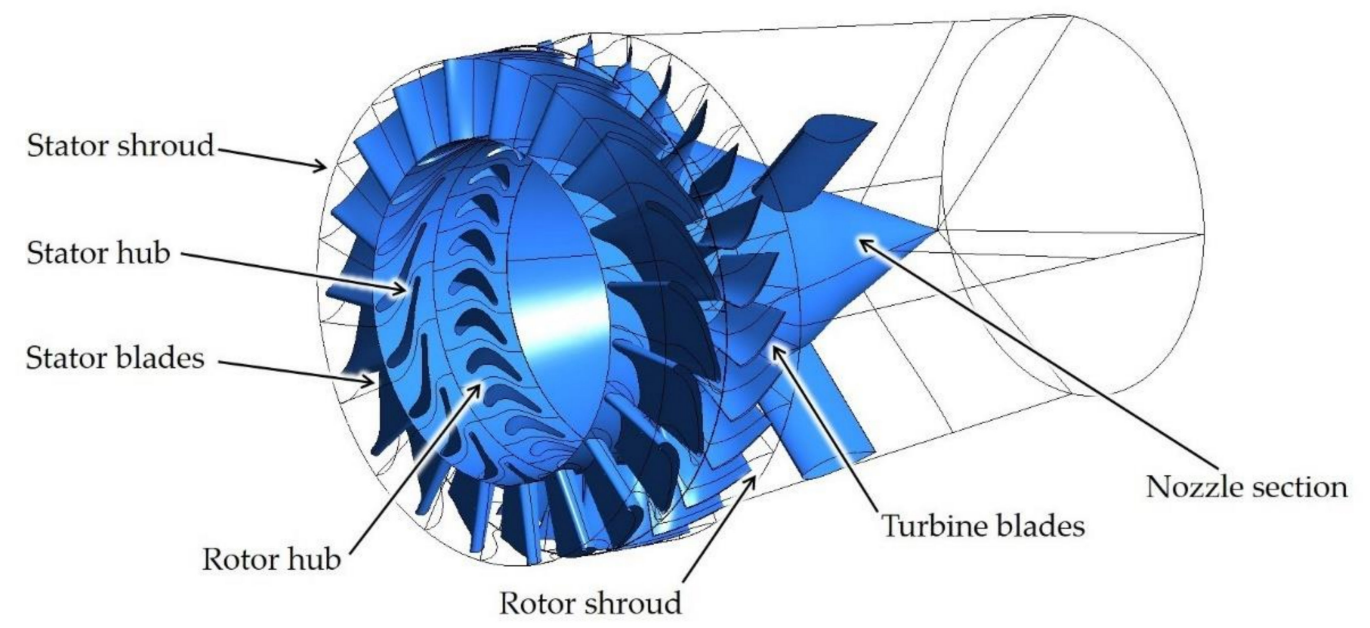

Figure 2. 3D model of the geometry of the turbine and nozzle section of the iSTC-21v jet engine.

The 3D model of the turbine and nozzle section is shown in Figure 2. The turbine section consists of the stator hub and stator shroud with 19 stator vanes. The pressure turbine consists of the rotor hub, rotor shroud and 27 turbine blades. According to the geometry, the finite element model was created. In our case, the model was prepared and meshed in the ANSYS software. The boundary conditions for 10 operational regimes were defined in the ANSYS CFX software. Inputs for the 10 performed CFD analyses are summarized in Table 1 . The boundary conditions were defined by the temperature and 
pressure in front of the turbine and by the speed. All of these parameters were measured experimentally in laboratory conditions $[35,36]$. These data were experimentally measured on the iSTC-21v jet engine specifically for the purpose of the application of the proposed methodology in our Laboratory of Intelligent Control Systems of Aircraft Engines.

Table 1. Overview of boundary conditions for the computational fluid dynamics (CFD) analyses.

\begin{tabular}{cccc}
\hline Regime & Temperature- $\left.\boldsymbol{T}_{\mathbf{3 t}}{ }^{\circ} \mathbf{C}\right)$ & ${\text { Pressure- } \boldsymbol{P}_{\mathbf{3 t}}(\mathbf{P a})}$ & Speed (rpm) \\
\hline 1 & 824.0 & 197,700 & 36,079 \\
2 & 851.0 & 197,900 & 36,110 \\
3 & 862.6 & 211,300 & 37,920 \\
4 & 891.3 & 229,000 & 39,960 \\
5 & 914.3 & 264,400 & 41,660 \\
6 & 942.9 & 268,200 & 44,080 \\
7 & 977.9 & 288,100 & 46,020 \\
8 & 1007.0 & 307,300 & 47,860 \\
9 & 1067.0 & 339,100 & 50,120 \\
10 & 1127.0 & 361,300 & 51,990 \\
\hline
\end{tabular}

The third step shown in Figure 1 represents the utilization of the CFD analysis results as the inputs for the ANN. These coefficients are used for the ANN training in order to predict the thermal fields in the specific nodes with the positions defined in the chosen coordinate system. The last step shown in Figure 1 is linked up to the previous one, and it means the ANN is used during the life phase for the prediction of the temperature fields according to the measured data. In our case, as the input data, the experimental results presented in Table 1 were applied.

\subsection{Theory and Application of the CFD Method}

In the presented research, two conventionally used methods of physics and mathematics are integrated. The first one is the numerical CFD method, which is well-known, and the second one is the method based on the ANNs. The theory of the CFD and ANN is extensive, but in the following chapters, only substantial facts necessary for the novel methodology for the temperature fields prediction explanation are described [37].

The CFD method is known for a few decades, but its application for complex problems is still time-consuming. The CFD stands for computational fluid dynamics, which is a branch of fluid mechanics. The method uses numerical analysis and data structures to analyze and solve the problems involving fluid flows.

For a better understanding, the methodology is directly explained on the example of the iSTC-21v jet engine. The 3D model, in our case the 3D models shown in Figure 2, is imported into the ANSYS software, and the mesh for the particular parts is created. In our case, at first, the stator section of the turbine is meshed [38,39]. The 3D mesh is created by mapping the 2D mesh of the particular parts of the stator section. The mesh of the turbine stator section is shown in Figure 3a. In Figure 3b, the 3D mesh created on the basis of the geometry can be seen. It is the rotor section of the turbine of the iSTC-21v jet engine. Finally, the meshed nozzle, as can be seen in Figure 3c, is created. All three parts in our case consist of the hexa elements $[40,41]$. 

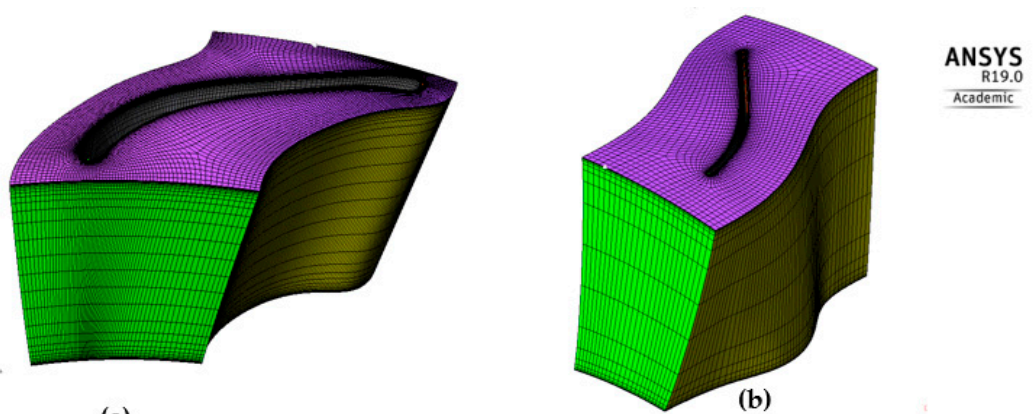

(a)

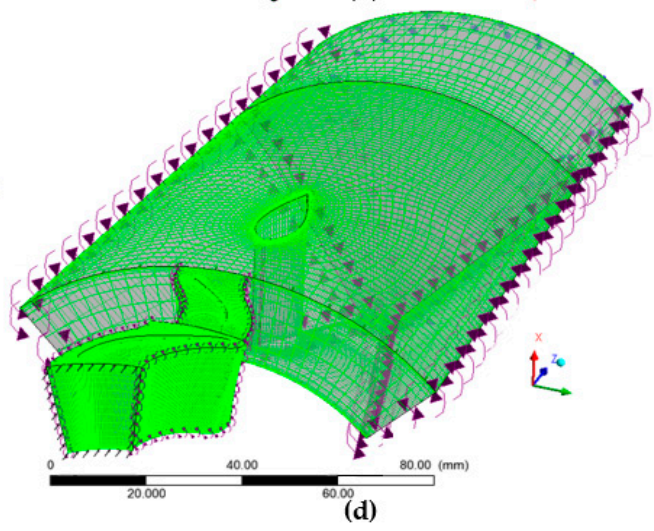

(c)

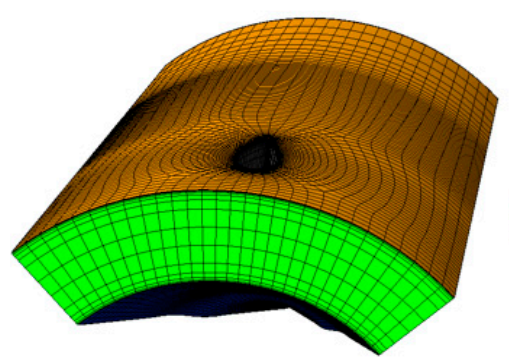

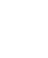

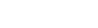

)

Figure 3. (a) Meshed stator blade of the iSTC-21v jet engine; (b) meshed turbine blade of the iSTC-21v jet engine; (c) meshed nozzle of the iSTC-21v jet engine; (d) computational CFD domain of the turbine section and nozzle.

The overall approach for the solution of the presented problem starts with the definition of the CFD simulation. In order to define and set the above-mentioned simulation, the Turbomachinery wizard was used. The mesh of the stator, rotor and nozzle was imported and combined, as it is shown in Figure 3d. The Frozen Rotor simulation was performed and then modified to define the Transient Rotor-Stator simulation. The Transient Rotor-Stator simulation was performed using the steady-state Frozen Rotor for the initial guess. Finally, the results of this analysis are used for further processing. The final model prepared for the CFD simulation is presented in Figure $3 d$, where the boundary conditions are applied for one regime. Subsequently, boundary conditions were applied for other regimes. For the particular regimes, the rotor speeds, temperatures and pressures were applied according to the obtained results from the experimental measurements performed on the iSTC-21v jet engine (summarized in Table 1). The axis of the rotation for the simulation is the Z-axis, as shown in Figure 3d.

The CFD model consists of 2,756,789 elements, the element size for the blade is $0.0035 \mathrm{~mm}, \mathrm{y}+$ value is 0.9565 , the $2 \mathrm{D}$ mesh of the blade is shown in Figure 4 . The general information of the turbine vane and blade is listed below. The chord of the turbine blade is $25 \mathrm{~mm}$, the span of the turbine blade is $26 \mathrm{~mm}$, the pitch has a value of $17.5 \mathrm{~mm}$ for the blade. The Inlet angle is 20.5 degrees, and the outlet angle is 58 degrees. The distance between the stator vane and rotor blade of the turbine is $12 \mathrm{~mm}$. Chord line of the stator vane is $40 \mathrm{~mm}$, the span of the vane is $25 \mathrm{~mm}$, and the pitch is $22 \mathrm{~mm}$. The turbulent model for the simulation is chosen, the shear stress transport model, which is one of the most accurate models. This model of turbulence, with the help of the transmission of turbulent shear stresses, provides a highly accurate prediction of the onset flow separation under an adverse pressure gradient. It is essential to emphasize the main goal of the article, which is the application of the novel methodology; therefore, there it is not essential to dedicate more attention to the CFD computations. 


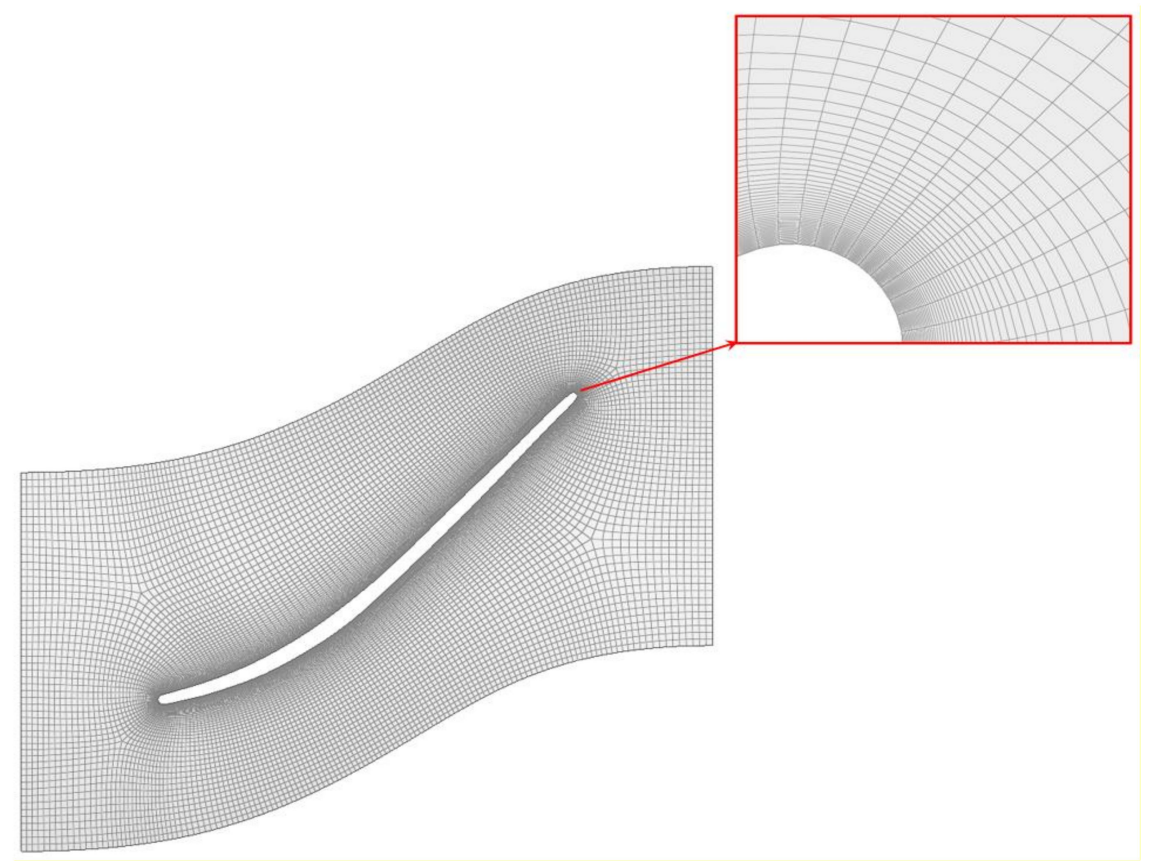

Figure 4. Turbine blade mesh topology of the iSTC-21v jet engine.

\subsection{Theory and Application of the Method Based on the ANN}

Generally, ANNs try to approximate or simulate the neurophysiological structure of the human brain. The large complex of the network consists of interconnected neural cells, also called neurons. Each neuron receives signals from the neurons connected to it through the dendrites and conveys a signal using the axon. A simple mathematical model for this process considers the output of a unit as a function. The function is called the activation function, which is usually nonlinear. The coefficients of the transformation (connections between the neurons) are called biases; the other coefficients called weights determine the response and can be adapted depending on how the connection is activated during the training [42-45].

There are many types of ANN with different architectures, activation functions, training functions, etc. In the proposed methodology, the feed-forward back propagation neural network was applied [46]. The ANN architecture is shown in Figure 5. For the ANN, the sigmoid function $S(x)$ can be used:

$$
S(x)=\frac{1}{1+e^{-x}}
$$

In our case, the symmetrical sigmoid as an alternative to the sigmoid function was used, according to the formula:

$$
S(x)=2 s(x)-1=\frac{1-e^{-x}}{1+e^{-x}}
$$

As the training algorithm scaled, conjugate gradient (SCG) for the supervised learning was used. The SCG updates weight and bias values according to the scaled conjugate gradient method $[47,48]$. The SCG can train any ANN as long as its weight, net-input, and transfer functions have derivative functions. In order to calculate derivatives of the performance with respect to the weight and bias variables $x$, backpropagation was used [26].

The architecture of the ANN used for the temperature prediction is in Figure 5. The ANN for the prediction of the temperature fields consists of the input layer with three neurons, three hidden layers and of the output layer [20]. 


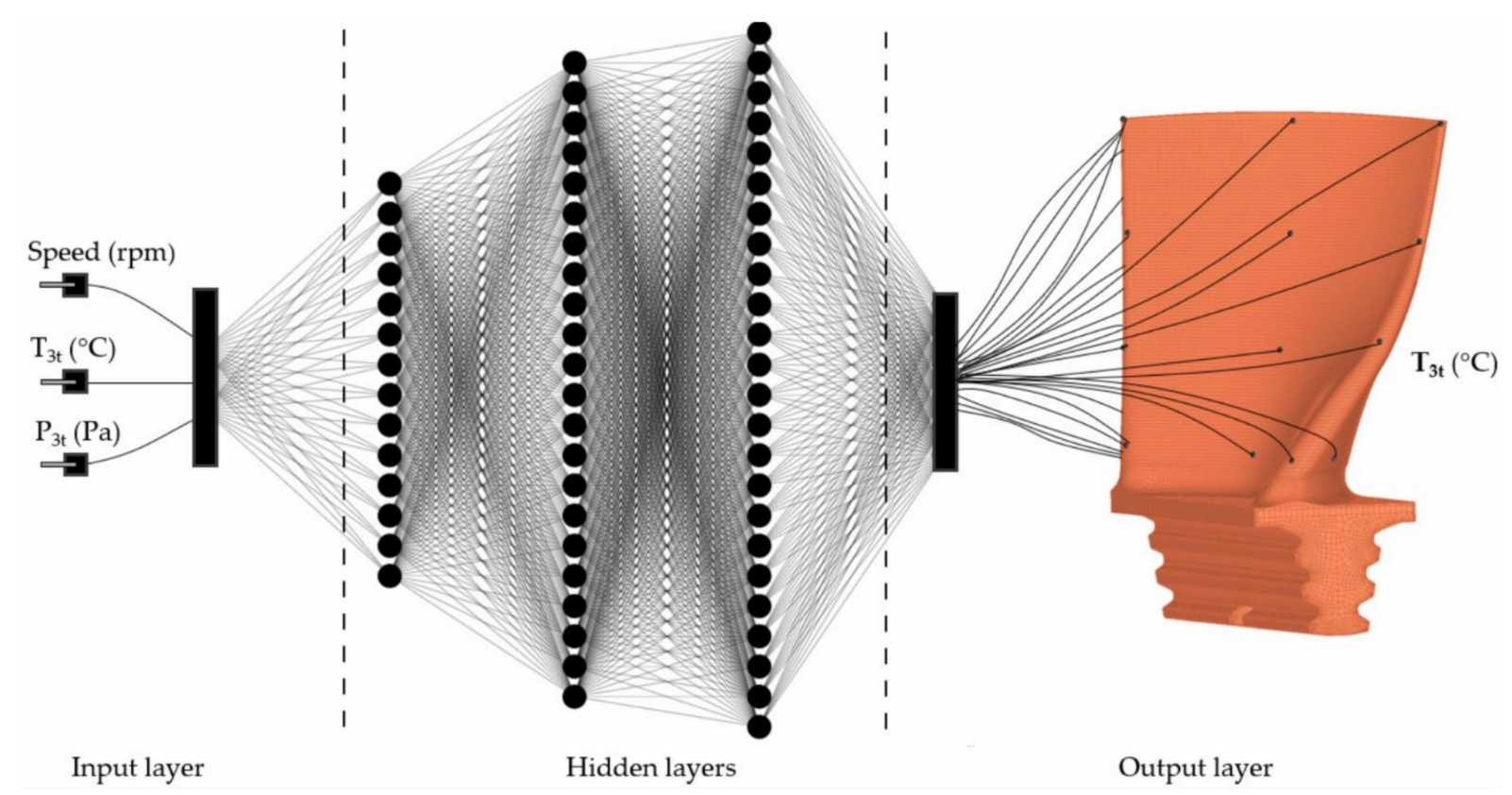

Figure 5. Architecture of the proposed artificial neural networks (ANN) for the temperature field prediction of the turbine blade.

During the training process, the measured data summarized in Table 1 were used. The detailed results obtained from the CFD analyses, according to the methodology presented in Figure 1, that were used as the inputs for the ANN to predict the temperatures are described in Section 3, Results. The input layer consists of the input temperature $T_{3 \mathrm{t}}$, pressure $P_{3 t}$ and rotor speed. The output layer is created by the predicted temperatures, in our case calculated for 24 points selected as the specific nodes on the surface of the turbine blade of the iSTC-21v jet engine. In the output layers, there are also temperatures $T_{3 t}$, estimated using new technology, which is quicker than conventional methods as CFD and other methods.

\section{Results}

Results consist of two parts. The first part is created by the results from the CFD analyses, which are subsequently used as the inputs for the ANN. The second part involves results with the predicted temperatures as the results from the ANN.

In Figure 6, the temperature fields on the surface of the turbine blade estimated in the ANSYS CFX software are shown. The visualized results correspond to the first regime summarized in Table 1. Temperatures on the surface of the turbine blades are in the Kelvin units. The analysis was performed for 10 specified regimes, and the temperatures were recorded for the specific nodes with the corresponding $x, y$, and $z$ coordinates. These coordinates also correspond to the points shown on the surface blade in Figure 6. The example from this record from the CFD analyses only for five chosen coordinates is shown in Table 2. The temperatures were calculated in 24 nodes for the purposes of the methodology verification. However, it is possible to perform temperature analyses for so many nodes as necessary [49]. Elapsed time for temperature fields prediction using CFD for one regime is $1 \mathrm{~h}, 42 \mathrm{~min}$ and $44.7 \mathrm{~s}$. 


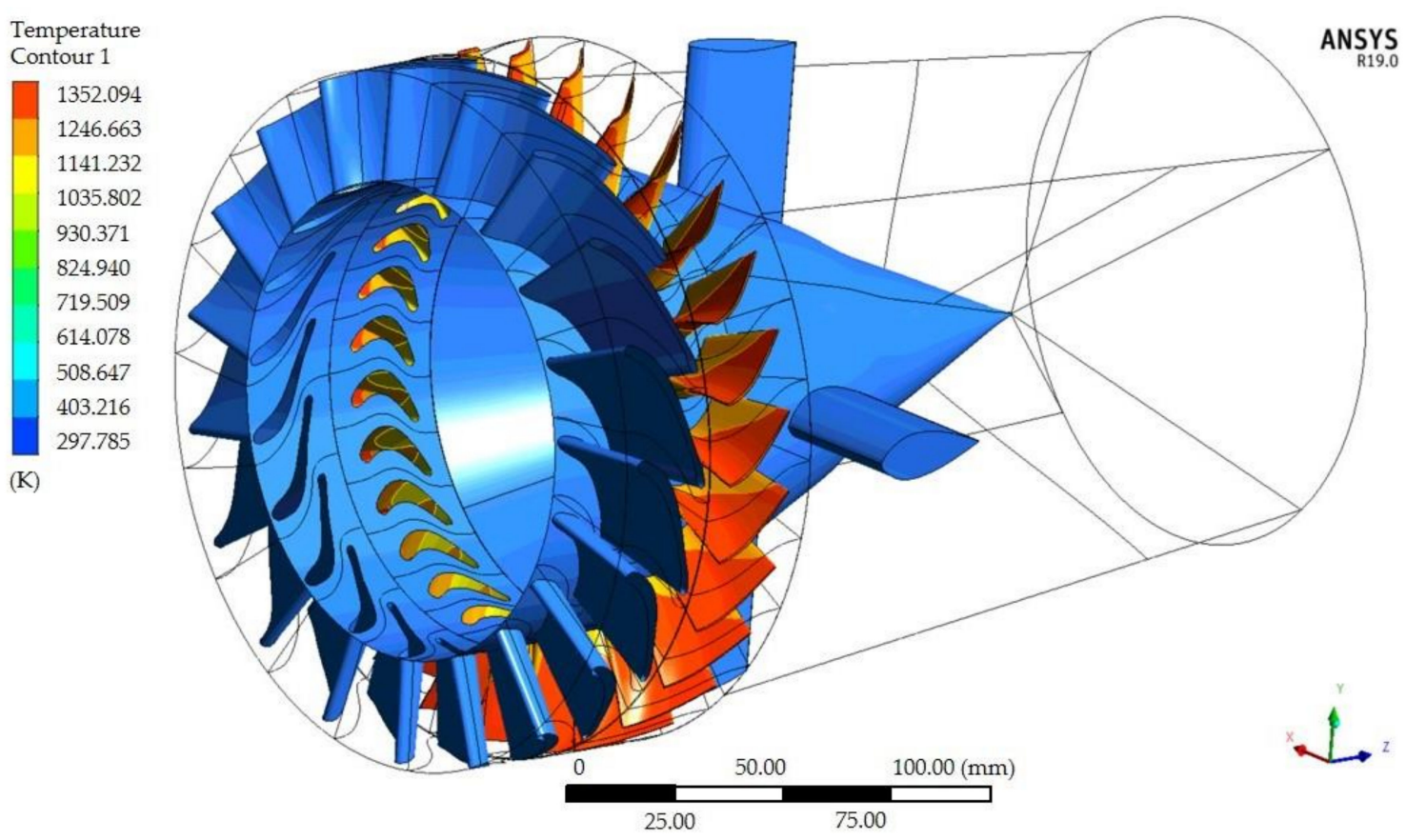

Figure 6. Temperature fields of the turbine blade of the iSTC-1v jet engine computed using ANSYS CFX software.

Table 2. Estimated temperatures using ANSYS CFX software for the chosen nodes of the blade.

\begin{tabular}{cccc}
\hline Coordinate $\mathbf{X}$ & Coordinate $\mathbf{Y}$ & Coordinate $\mathbf{Z}$ & Temperature $\left({ }^{\circ} \mathbf{C}\right)$ \\
\hline 80.062 & 6.408 & 3.538 & 1044.510 \\
55.084 & 2.013 & 14.732 & 955.635 \\
60.602 & 2.115 & 13.566 & 964.962 \\
65.514 & 1.040 & 13.765 & 977.080 \\
72.748 & -0.077 & 13.519 & 998.633 \\
\hline
\end{tabular}

Temperatures at the specific nodes and corresponding coordinates were used for the ANN training. In our case, temperatures in 24 nodes with corresponding coordinates for each of the 10 runs representing 10 operational regimes (Table 1) were determined. It means that 240 temperatures for the training process of the ANN were used.

In Figure 7, the data distribution and the corresponding linear approximation for the ANN training, validation and test process are shown. The data are divided for training $70 \%$ (blue line in Figure 7), 15\% for validation (green) and 15\% for the test (red part line in Figure 7). All values from the training, validation and testing process are shown in Figure 6 (black line).

The results determined by the neural network are presented in Figure 8, where two types of data are shown. There are ten operation regimes of the iSTC-21v jet engine and the temperatures on the blade surface in the specific nodes. It means that each line corresponds to one operation regime of the jet engine, and each dot corresponds to a specific node.

In Figure 8, results from the research based on the methodology described in Chapter 2.1 are presented. From the figure, the comparison between calculated temperatures in the specific nodes on the surface of the turbine blade is shown. The red lines correspond to the temperatures computed by the ANN, and the black lines are the temperatures calculated using the CFD method, whereby one pair of the black and red lines corresponds to one particular operation regime (according to Table 1) of the jet engine. Elapsed time for temperature fields prediction using ANN for one regime is $0.0027645 \mathrm{~s}$. As it can be seen, the prediction time using ANN is almost immediate; thus, the methodology (Figure 1) applied in the iSTC-1v jet engine is really prompt. The peak in Figure 9 could be caused due to the mesh character in the trailing edge are (Figure 4), but there could be more reasons that have an impact on the results (Figure 9). The airfoil in the tail section of the 
turbine blade is the narrowest part, and in this area, the mesh could be finer; another reason can be nonuniform flow in this area, turbulence or geometrical phenomena. It is essential to point out that the ANN is working properly; thus, the proposed methodology is correct. However, for application on the specific parts of the jet engine, the CFD model must be optimized, not only from the aerodynamic and numerical simulation point of view. Furthermore, the preliminary results obtained by the ANN can serve for the specification of the parts of the model that must be optimized. Based on the presented results, it is possible to decide if the mesh size is suitable for the integration of the CFD model into the ANN calculations.

Test: $\mathrm{R}=0.99741$

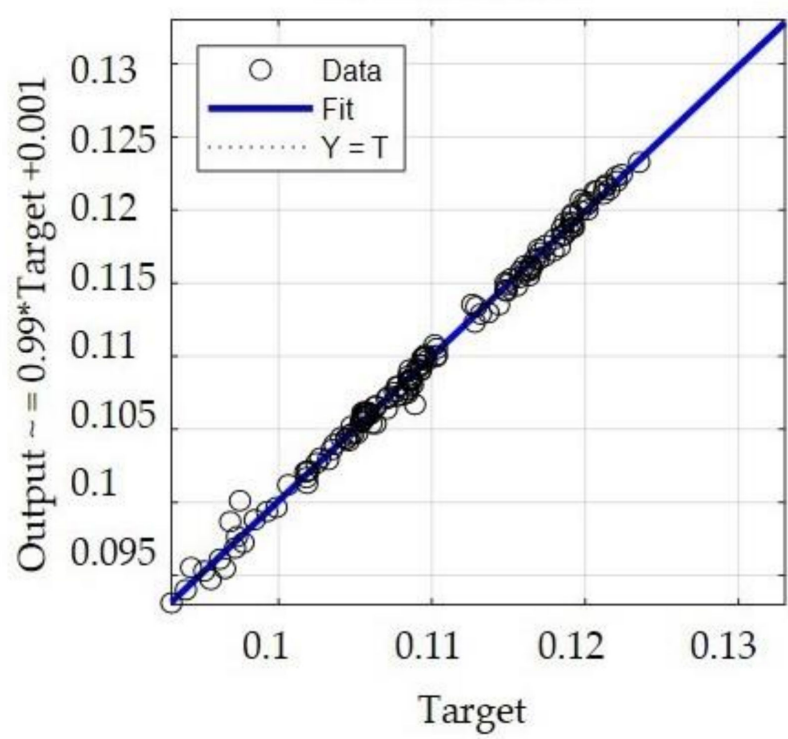

Test: $\mathrm{R}=0.99508$

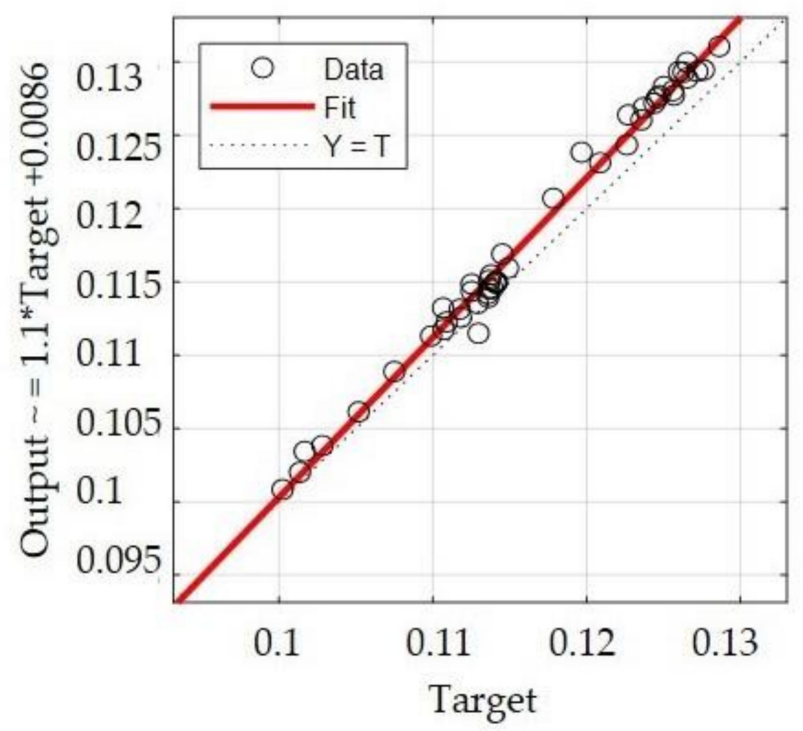

Test: $\mathrm{R}=0.99822$

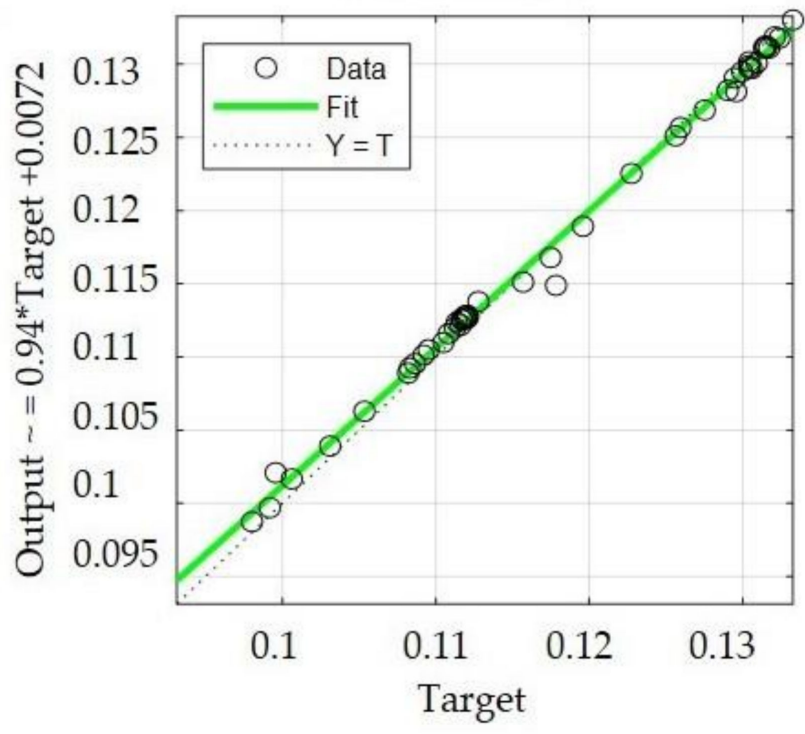

Test: $\mathrm{R}=0.99371$

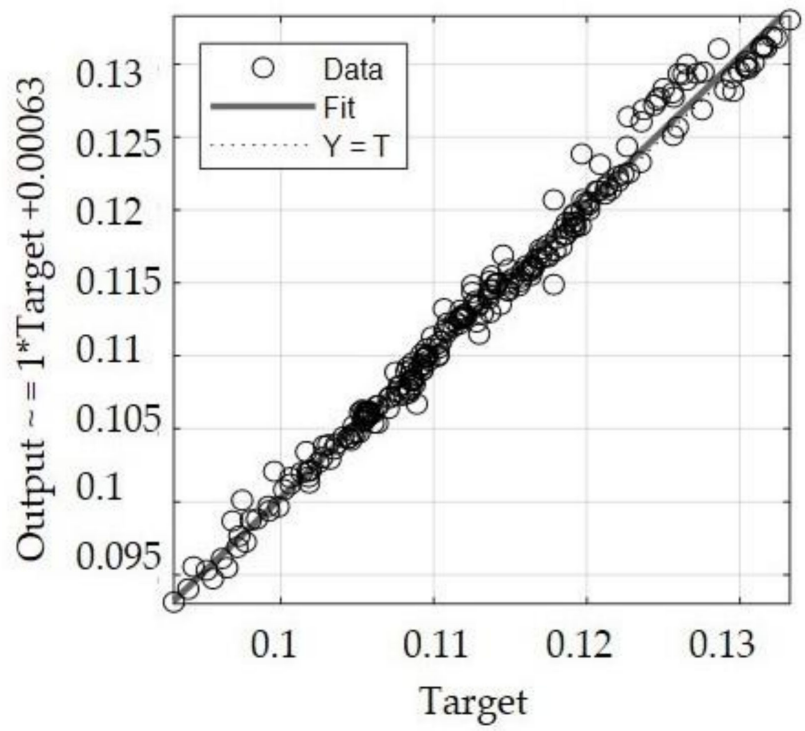

Figure 7. Statistical data for the training process of the ANN for temperature field prediction at specific nodes. 


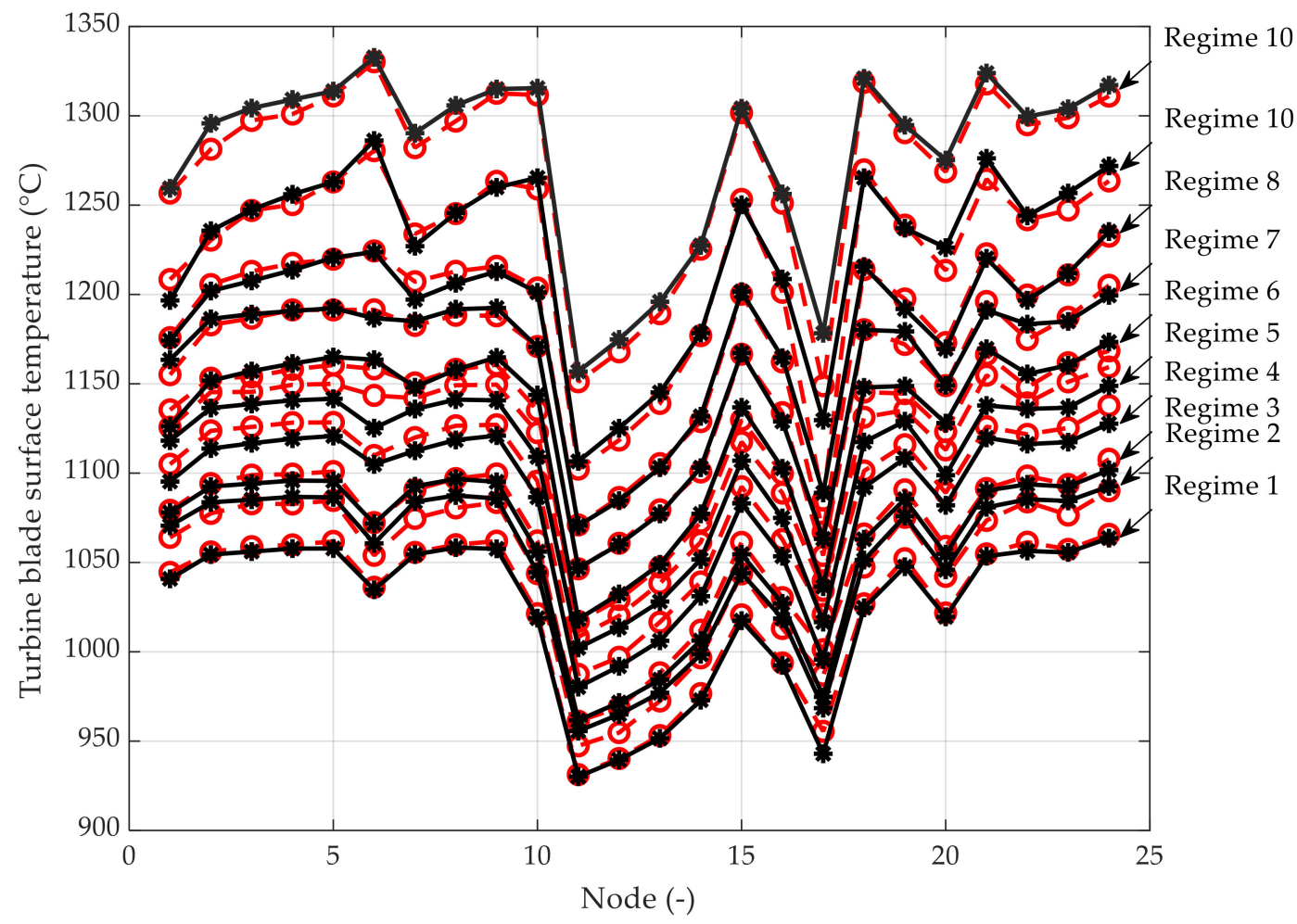

Figure 8. Predicted temperatures in specific nodes representing the chosen positions on the surface of the turbine blade.

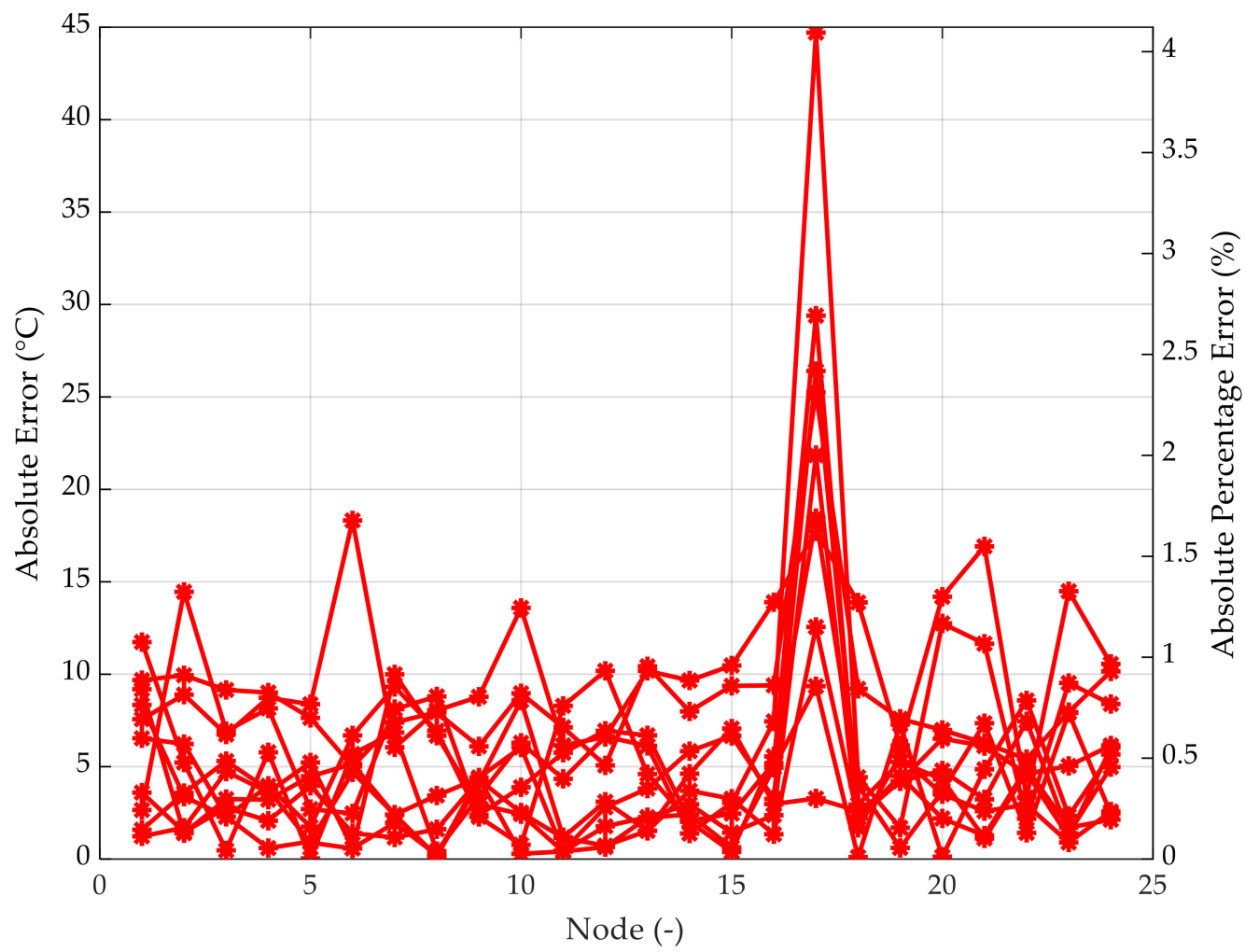

Figure 9. Computed absolute errors of the temperatures determined for each node for the specified operational regimes.

The nodes in Figure 8 corresponds to the coordinates specified, where these specific points are directly shown on the surface of the turbine blade of the iSTC-21v jet engine. 
Qualitative coefficients of the performed analyses in the form of the estimated errors are summarized in Table 3. It is essential to emphasize that the trained neural network can now be used for other regimes to predict temperatures.

Table 3. Estimated errors of the predicted temperatures.

\begin{tabular}{ccc}
\hline MAE $\left({ }^{\circ} \mathbf{C}\right)$ & MAPE $(\%)$ & Max. Difference $\left({ }^{\circ} \mathbf{C}\right)$ \\
\hline 5.59 & 0.5 & 44.7 \\
\hline
\end{tabular}

In Table 3, mean absolute error (MAE) [47] was calculated based on the predicted temperatures according to Equation (3):

$$
M A E=\frac{1}{n} \sum_{n}^{1}\left|y_{i}-\hat{y}_{i}\right|
$$

The mean absolute percentage error (MAPE) was calculated according to the relationship:

$$
M A P E=\frac{100}{n} \sum_{n}^{1} \frac{\left|y_{i}-\hat{y}_{i}\right|}{y_{i}}
$$

The computed error for each point is shown in Figure 9, where the development of the error for the chosen nodes can be clearly seen. The maximal absolute error reached the value of $44.7^{\circ} \mathrm{C}$. For the comparison, in Figure 9 also the visualization of the absolute percentage error with the mean value of $0.5 \%$ can be seen. Estimated errors in Table 3 were computed in the Matlab software. The maximum difference is the maximal difference between the temperature predicted by the CFD methodology and the temperature estimated using the methodology based on the ANN. In Figure 9, each line corresponds to the errors calculated for the particular regimes. There are 10 lines, each for one regime, and dots correspond to the specific node on the surface of the turbine blade of the iSTC-21v experimental jet engine.

As it was already mentioned, ANN is trained on 10 operation regimes; furthermore, trained ANN is used for predicting temperatures for more regimes. Thus, in Figure 10, the overview of predicted temperatures for 1800 boundary conditions (engine operation conditions) for the chosen 24 nodes representing the points at the turbine blade of the iSTC-21v jet engine can be seen. It is necessary to emphasize that only data from operation regimes 400 to 1400 are relevant due to the training process of ANN.

A created ANN is used for the prediction of other regimes apart from ten trained regimes, and the results are in Figure 10; in the figure, it can be seen that data from 0 to 400 and from 1400 to 1800 regimes cannot be included for the result evaluation. The reason for the exclusion of these regimes is that during the training process, there were not included data for lower regimes, so, for example, there are not computed temperatures for the ambient conditions, etc. It is essential to emphasize that the main purpose of the proposed article is to demonstrate methodology and other regimes that can be included in the additional research; nevertheless, the results have shown a high level of accuracy and proved the fact that it is possible to predict temperatures using ANN. 


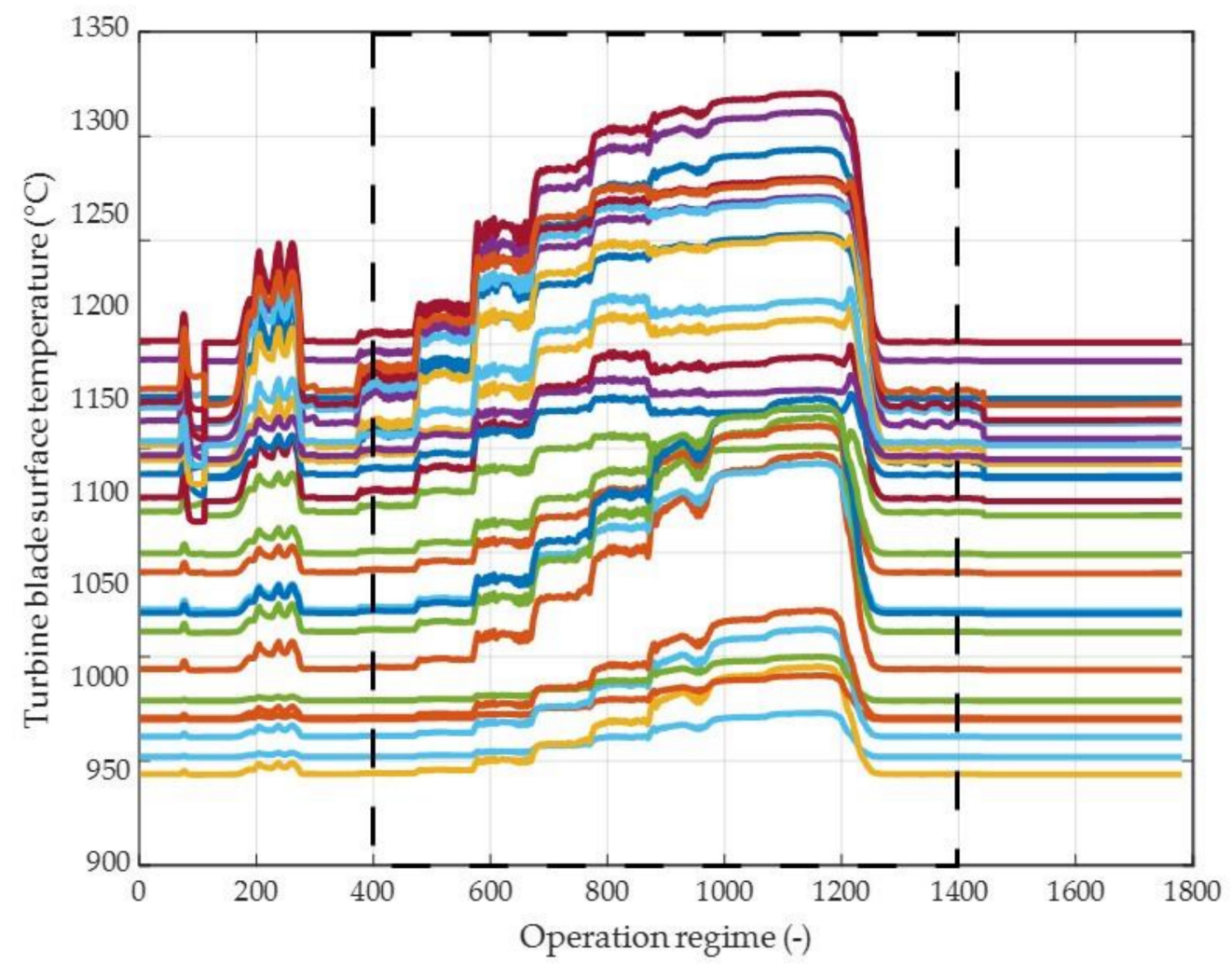

Figure 10. Estimated temperatures for one whole engine run using the new methodology based on the ANN.

\section{Discussion}

The results of the proposed methodology presented in the article confirm the correctness of the methodology based on the ANN for prediction of the temperatures on the surface of the turbine blades at specific nodes representing the points defined in the coordinate system. The main goal of the article was to verify the proposed methodology in real practice. Therefore, the ANN was at first used for the prediction of temperatures on the surface of the turbine blade and consequently applied and verified on the experimental iSTC-21v jet engine. In addition, the goal of the research was to develop the methodology that is able to predict temperatures on the turbine blade immediately with significantly eliminated computational and time demands and at the same time the methodology that could be accordingly applied on any other engines or their parts.

The proposed article involves not only the description of the methodology but also its direct practical application, also showing partial results that lead to the fulfillment of the main goal of the research. For the purposes of the methodology verification, the 3D model of the turbine and nozzle section for the CFD studies based on the iSTC-21v engine was created. The CFD analysis results are presented in Figure 6 shows one of the 10 performed CFD analyses. Using the CFD ANSYS software, the temperature fields were estimated for the iSTC-21v jet engine, and subsequently, the analyses were performed for 10 specified operation regimes of the engine in order to obtain inputs for the neural network.

The most valuable contribution of the proposed methodology is presented in Figure 9, where the dependency between the data computed using the CFD and ANN method can be clearly seen. The figure shows the temperatures predicted using the ANN for the chosen 10 operational regimes of the jet engine in the specific nodes representing the points on the surface of the turbine blade.

The new methodology is applied to other regimes (Figure 10), where are predicted temperatures for 1800 regimes. It is necessary to point out again that the relevant results presented in Figure 10 are emphasized with the dashed black line due to the character of the training data. This is caused due to the character of the training data obtained 
from the CFD analyses. The training inputs estimated by the CFD method involved just 10 operational regimes of the jet engine summarized in Table 1 . However, there are not regimes included for the initial state during the no run of the engine; thus, in order to create a more accurate method, it is necessary to include some other regimes, for example, for ambient temperature and some other lower regimes. These regimes will be included in the future, and it will be the scope for further research.

\section{Conclusions}

Prediction of the temperature changes in the material of the jet engine turbine blades, the impact of the temperatures on the stress, deformation and fatigue analyses is undoubtedly an especially important part of the engineering, which helps mainly during the development and monitoring of the selected parts of the jet engine. For the jet engines and also other parts of aircraft structures, monitoring and predictions are particularly crucial because any structural damage can lead to aircraft accidents.

The main goal of the performed research was to develop a new faster method for temperature prediction. The fact that the new methodology is faster in comparison with methods like CFD is irrefutable. It can be proved by comparison times for prediction temperature fields using CFD and ANN for one operation regime. In proposed research methodology is applied on an iSTC-21v jet engine, and elapsed time using the CFD method is one h, $42 \mathrm{~min}$ and $44.7 \mathrm{~s}$, elapsed time using the new method is $0.0027645 \mathrm{~s}$. From the results presented in the article, it can be concluded that the proposed methodology fulfilled this goal. The new methodology based on the ANN is able to predict temperatures of the turbine blades in the specific point almost in real time; thus, the method can be used for monitoring the temperatures also during the runs in the real operation of the jet engine, forasmuch as the new methodology predicts the temperatures immediately. The results presented in the article proved that the idea is correct. Furthermore, thanks to this methodology, it is possible to predict temperatures for many operation regimes. The novel method offers an incomparable faster prediction of temperatures even in real time, in comparison with the conventionally used CFD method, which needs for the prediction of temperatures for one regime several minutes or even hours according to the complexity of the simulation model and hardware performance.

For a better explanation of the proposed methodology and also for the verification purposed, the input data for the predictions, namely temperatures, pressures and rotor speed, were measured in the laboratory condition on the iSTC-21v experimental engine. It is essential to point out the originality of the article, which is the application of the ANN for the temperature prediction and its application on the iSTC-21v jet engine.

The methodology was applied for the chosen 24 points at the surface of the turbine blade; however, the proposed methodology can also be applied to other points of the turbine blades. Further improvement of the methodology is also expected if more operational regimes of the jet engine will be examined and added.

The performed analyses of statistical errors obtained as a result of the performed calculations showed that the artificial neural network is able to reveal the problems that can occur during the preparation of the CFD model. In our case, one of the chosen nodes in Figure 9 exhibits a statistically significant error with the value of $4.121 \%$, which is probably a consequence of the meshing process, turbulent model or errors resulting from the geometry in this narrow part of the turbine blade. However, the above-mentioned issues do not influence the quality of the proposed methodology, the main goal of which was to apply the neural network for the temperature field prediction. In our case, the methodology was verified on the turbine blade surface, but one of the advantages of the methodology is that it can be applied for the temperature prediction of any other jet engine or its parts.

The result of the integration of the CFD model and the ANN approach is that the time demands for the calculations of the temperature fields are significantly reduced, and thus during the optimization process of the jet engines or of the components, it is not necessary 
to wait for the results of the time-consuming CFD simulations and therefore, the calculation results can be applied in the real time also, for example, during the operation of the jet engine. Thus, it is possible to predict life and other temperature-dependent parameters mentioned in the background research described in detail in the introduction.

It can be concluded that the proposed methodology was confirmed and verified also on the basis of experimental results, and the achieved results in this area will serve as a basis for the further research, development and application of jet engines. Based on the results presented in the article, it is clear that the methodology is convenient for predicting the temperatures of a chosen engine part, further research will focus on the optimization of the CFD model, involving its mesh and parameters. Because the more precisely processed CFD model is used, the more precise results will be obtained from the calculations using the neural networks.

Author Contributions: Methodology, M.S.; software, M.S.; validation, M.S.; formal analysis, K.S.; investigation, M.S.; resources, K.D.; data curation, M.S.; writing-original draft preparation, M.S.; writing-review and editing, K.D.; visualization, M.S.; supervision, K.S.; project administration, K.S.; funding acquisition, M.S. All authors have read and agreed to the published version of the manuscript.

Funding: This research was funded by the Slovak Research and Development Agency, grant number APVV-18-0248 and grant number APVV-17-0184 and the Research Agency, ITMS code number 3130117557.

Institutional Review Board Statement: Not applicable.

Informed Consent Statement: Not applicable.

Conflicts of Interest: The authors declare no conflict of interest.

\section{References}

1. Royce, R. The Jet Engine, 5th ed.; John Wiley \& Sons, Ltd on behalf of Rolls-Royce plc.: London, UK, 2015; ISBN 978-1-119-06599-9.

2. Blachnio, J.; Bogdan, M.; Zasada, D. Increased Temperature Impact on Durability of Gas Turbine Blades. Eksploat. Niezawodn. 2017, 19, 48-53. [CrossRef]

3. Janicki, G.; Pezouvanis, A.; Mason, B.; Ebrahimi, M.K. Turbine Blade Vibration Measurement Methods for Turbocharges. Am. J. Sens. Technol. 2014, 2, 13-19. Available online: http://pubs.sciepub.com/ajst/2/2/1/ (accessed on 22 January 2021).

4. Rezazadeh Reyhani, M.; Alizadeh, M.; Fathi, A.; Khaledi, H. Turbine blade temperature calculation and life estimation-A sensitivity analysis. Propuls. Power Res. 2013, 2, 148-161. [CrossRef]

5. Zhang, Z.; Yang, G.; Hu, K. Prediction of Fatigue Crack Growth in Gas Turbine Engine Blades Using Acoustic Emission. Sensors 2018, 18, 1321. [CrossRef]

6. Vasilyev, B.; Nikolaev, S.; Raevskiy, M.; Belov, S.; Uzhinsky, I. Residual Life Prediction of Gas-Engine Turbine Blades Based on Damage Surrogate-Assisted Modeling. Appl. Sci. 2020, 10, 8541. [CrossRef]

7. Zhu, S.-P.; Yue, P.; Yu, Z.-Y.; Wang, Q. A Combined High and Low Cycle Fatigue Model for Life Prediction of Turbine Blades. Materials 2017, 10, 698. [CrossRef] [PubMed]

8. Mai, T.D.; Ryu, J. Effects of Leading-Edge Modification in Damaged Rotor Blades on Aerodynamic Characteristics of HighPressure Gas Turbine. Mathematics 2020, 8, 2191. [CrossRef]

9. Horlock, J.H.; Torbidoni, L. Turbine blade cooling: The blade temperature distribution. Proc. Inst. Mech. Eng. Part A J. Power Energy 2006, 220, 343-353. [CrossRef]

10. Zhang, F.; Liu, Z.; Liu, Z.; Diao, W. Experimental Study of Sand Particle Deposition on a Film-Cooled Turbine Blade at Different Gas Temperatures and Angles of Attack. Energies 2020, 13, 811. [CrossRef]

11. Masci, R.; Sciubba, E. A Gas Turbine Cooled-Stage Expansion Model for the Simulation of Blade Cooling Effects on Cycle Performance. Int. J. Turbomach. Propuls. Power 2019, 4, 36. [CrossRef]

12. Granovskiy, A.; Gribin, V.; Lomakin, N. Experimental and Numerical Study of Transonic Cooled Turbine Blades. Int. J. Turbomach. Propuls. Power 2018, 3, 16. [CrossRef]

13. Sakamoto, J.; Tada, N.; Uemori, T.; Kuniyasu, H. Finite Element Study of the Effect of Internal Cracks on Surface Profile Change due to Low Loading of Turbine Blade. Appl. Sci. Basel 2020, 10, 4883. [CrossRef]

14. Miao, Q.; Li, H.N.; Ding, W.F. On the temperature field in the creep feed grinding of turbine blade root: Simulation and experiments. Int. J. Heat Mass. Transf. 2020, 147, 118957. [CrossRef]

15. Tang, W.; Yang, L.; Zhu, W.; Zhou, Y.; Guo, J.; Lu, C. Numerical Simulation of Temperature Distribution and Thermal-Stress Field in a Turbine Blade with Multilayer-Structure TBCs by aFluid-Solid Coupling Method. J. Mater. Sci. Technol. 2016, 32, 452-458. [CrossRef] 
16. Zhu, W.; Wang, J.W.; Yang, L.; Zhou, Y.C.; Wei, Y.G.; Wu, R.T. Modeling and simulation of the temperature and stress fields in a 3D turbine blade coated with thermal barrier coatings. Surf. Coat. Tech. 2017, 315, 443-453. [CrossRef]

17. Baheta, A.T.; Leong, K.P.; Sulaiman, S.A.; Fentaye, A.D. CFD Analysis of Fouling Effects on Aerodynamics Performance of Turbine Blades. In Rotating Machineries; Springer Singapore Pte Ltd: Singapore, 2018; pp. 73-84. [CrossRef]

18. Bäcker, V.; Klocke, F.; Wegner, H.; Timmer, A.; Grzhibovskis, R.; Rjasanow, S. Analysis of the Deep Rolling Process on Turbine Blades using the FEM/BEM-Coupling. IOP Conf. Ser. Mat. Sci. 2010, 10, 012134. [CrossRef]

19. Gantasala, S.; Luneno, J.-C.; Aidanpää, J.-O. Investigating How an Artificial Neural Network Model Can Be Used to Detect Added Mass on a Non-Rotating Beam Using Its Natural Frequencies: A Possible Application for Wind Turbine Blade Ice Detection. Energies 2017, 10, 184. [CrossRef]

20. Zhang, C.-Y.; Wei, J.-S.; Wang, Z.; Yuan, Z.-S.; Fei, C.-W.; Lu, C. Creep-Based Reliability Evaluation of Turbine Blade-Tip Clearance with Novel Neural Network Regression. Materials 2019, 12, 3552. [CrossRef]

21. Liu, X.; Liu, Z.; Liang, Z.; Zhu, S.-P.; Correia, J.A.F.O.; De Jesus, A.M.P. PSO-BP Neural Network-Based Strain Prediction of Wind Turbine Blades. Materials 2019, 12, 1889. [CrossRef]

22. Liu, J.; Liu, J.; Yu, D.; Kang, M.; Yan, W.; Wang, Z.; Pecht, M.G. Fault Detection for Gas Turbine Hot Components Based on a Convolutional Neural Network. Energies 2018, 11, 2149. [CrossRef]

23. Chan, Y.-K.; Gu, J.-C. Modeling of Turbine Cycles Using a Neuro-Fuzzy Based Approach to Predict Turbine-Generator Output for Nuclear Power Plants. Energies 2012, 5, 101-118. [CrossRef]

24. Zhang, C.; Wei, J.; Jing, H.; Fei, C.; Tang, W. Reliability-Based Low Fatigue Life Analysis of Turbine Blisk with Generalized Regression Extreme Neural Network Method. Materials 2019, 12, 1545. [CrossRef]

25. Zhao, Q.; Bao, K.; Wang, J.; Han, Y.; Wang, J. An Online Hybrid Model for Temperature Prediction of Wind Turbine Gearbox Components. Energies 2019, 12, 3920. [CrossRef]

26. Khan, F.; Eker, O.F.; Khan, A.; Orfali, W. Adaptive Degradation Prognostic Reasoning by Particle Filter with a Neural Network Degradation Model for Turbofan Jet Engine. Data 2018, 3, 49. [CrossRef]

27. Kozakiewicz, A.; Jóźwiak, S.; Jóźwiak, P.; Kachel, S. Material Origins of the Accelerated Operational Wear of RD-33 Engine Blades. Materials 2021, 14, 336. [CrossRef]

28. Ciampolini, M.; Bigalli, S.; Balduzzi, F.; Bianchini, A.; Romani, L.; Ferrara, G. CFD Analysis of the Fuel-Air Mixture Formation Process in Passive Prechambers for Use in a High-Pressure Direct Injection (HPDI) Two-Stroke Engine. Energies 2020, 13, 2846. [CrossRef]

29. Andoga, R.; Főző, L.; Schrötter, M.; Češkovič, M.; Szabo, S.; Bréda, R.; Schreiner, M. Intelligent Thermal Imaging-Based Diagnostics of Turbojet Engines. Appl. Sci. Basel 2019, 9, 2253. [CrossRef]

30. Andoga, R.; Főző, L.; Kovács, R.; Beneda, K.; Moravec, T.; Schreiner, M. Robust Control of Small Turbojet Engines. Machines 2019, 7, 3. [CrossRef]

31. Spodniak, M.; Semrád, K.; Főző, L.; Pavlinský, J. FEM analysis of natural frequencies of jet engine iSTC-21v turbine blade. In Proceedings of the SAMI 2019, IEEE 17th World Symposium on Applied Machine Intelligence and Informatics, Herlany, Slovakia, 24-26 January 2019; pp. 287-292. [CrossRef]

32. Beneda, K.; Andoga, R.; Főző, L. Linear Mathematical Model for State-Space Representation of Small Scale Turbojet Engine with Variable Exhaust Nozzle. Period. Polytech. Transp. Eng. 2017, 46, 1-10. [CrossRef]

33. Andoga, R.; Főző, L. Near Magnetic Field of a Small Turbojet Engine. Acta Phys. Pol. A 2017, 131, 1117-1119. [CrossRef]

34. Főző, L.; Andoga, A.; Kovács, L.; Schreiner, M.; Beneda, K.; Savka, J.; Soušek, R. Virtual Design of Advanced Control Algorithms for Small Turbojet Engines. Acta Polytec. Hung. 2019, 16, 101-117. [CrossRef]

35. Kovács, R.; Főző, L.; Andoga, R. Calculation of flow in the gas turbine and the outlet tract using CFD methods. In Proceedings of the CINTI 2015-16th IEEE International Symposium on Computational Intelligence and Informatics, Budapest, Hungary, 19-21 November 2015; pp. 75-78. [CrossRef]

36. Korkmaz, K.B.; Werner, S.; Bensow, R. Verification and Validation of CFD Based Form Factors as a Combined CFD/EFD Method. J. Mar. Sci. Eng. 2021, 9, 75. [CrossRef]

37. Song, X.; Liu, M.; Hu, X.; Wang, X.; Liao, T.; Sun, J. Numerical Analysis of Flow across Brush Elements Based on a 2-D Staggered Tube Banks Model. Aerospace 2021, 8, 19. [CrossRef]

38. Sinagra, M.; Picone, C.; Aricò, C.; Pantano, A.; Tucciarelli, T.; Hannachi, M.; Driss, Z. Impeller Optimization in Crossflow Hydraulic Turbines. Water 2021, 13, 313. [CrossRef]

39. Shrestha, U.; Choi, Y.-D. A CFD-Based Shape Design Optimization Process of Fixed Flow Passages in a Francis Hydro Turbine. Processes 2020, 8, 1392. [CrossRef]

40. Celik, A.; Bonten, C.; Togni, R.; Kloss, C.; Goniva, C. A Novel Modeling Approach for Plastics Melting within a CFD-DEM Framework. Polymers 2021, 13, 227. [CrossRef]

41. Zhang, W.; Li, L.; Zhang, B.; Xu, X.; Zhai, J.; Wang, J. A Closed-Loop Optimized System with CFD Data for Liquid Maldistribution Model. Processes 2020, 8, 1332. [CrossRef]

42. Kliment, T.; Praslička, D.; Lipovský, P.; Draganová, K.; Zavodsky, O. Calibration of magnetometer for small satellites using neural network. Acta Phys. Pol. A 2017, 131, 1129-1131. [CrossRef]

43. Andoga, R.; Draganová, K.; Laššák, M. Inverse Neural Network Controller for Camera Gimbal Stabilization. Acta Avion. 2016, 18, 1-6. 
44. Recio-Colmenares, R.; Gurubel-Tun, K.J.; Zúñiga-Grajeda, V. Optimal Neural Tracking Control with Metaheuristic Parameter Identification for Uncertain Nonlinear Systems with Disturbances. Appl. Sci. Basel 2020, 10, 7073. [CrossRef]

45. Lee, A.; Geem, Z.W.; Suh, K.-D. Determination of Optimal Initial Weights of an Artificial Neural Network by Using the Harmony Search Algorithm: Application to Breakwater Armor Stones. Appl. Sci. Basel 2016, 6, 164. [CrossRef]

46. Deng, Q.; Shao, S.; Fu, L.; Luan, H.; Feng, Z. An Integrated Design and Optimization Approach for Radial Inflow Turbines-Part II: Multidisciplinary Optimization Design. Appl. Sci. Basel 2018, 8, 2030. [CrossRef]

47. Annala, L.; Äyrämö, S.; Pölönen, I. Comparison of Machine Learning Methods in Stochastic Skin Optical Model Inversion. Appl. Sci. Basel 2020, 10, 7097. [CrossRef]

48. Draganová, K.; Laššák, M.; Praslička, D.; Kán, V. Attitude-Independent 3-axis accelerometer calibration based on adaptive neural network. Procedia Eng. 2014, 87, 1255-1258. [CrossRef]

49. Spodniak, M.; Semrád, K.; Šmelko, M.; Főző, L.; Andoga, R.; Draganová, K.; Szabo, S. Estimation of Magnetic Microwire Mechanical Properties by FEM Modeling. Acta Phys. Pol. A 2020, 137, 674-676. [CrossRef] 